\title{
Postirradiated and Nonirradiated Gliosarcoma: Immunophenotypical Profile
}

\author{
Lee C. Ang, James R. Perry, Juan M. Bilbao, Wayne Ozane, Eva Peschke, \\ Beverley Young and Nahid Nelson
}

\begin{abstract}
Background: Thirty-one gliosarcomas (25 nonirradiated and 6 postirradiated tumors) were selected based on the presence of two distinctive areas: a malignant gliomatous and a sarcomatous component. In all cases, the sarcomatous component appears like fibrosarcoma or malignant fibrous histiocytoma. Two tumors showed additional areas consisting of osteochondroid differentiation. Methods: All tumors were examined using antibodies against Ulex europaeus agglutinin I (UEA), glial fibrillary acidic protein (GFAP), vimentin (VM), epithelial membrane antigen (EMA), desmin, collagen IV, alpha-1-antitrypsin ( $\alpha-1-A T)$ and smooth muscle actin (SMA). Results: While the VM highlighted the sarcomatous areas of all tumors there were only scattered spindle cells that were GFAP-positive in the same areas. The $\alpha$-l-AT was diffusely reactive in the sarcomatous areas in 20 cases. Focal immunoreactivity was seen with SMA (20 tumors), UEA (8 tumors), EMA (5 tumors), collagen IV (5 tumors) and desmin (4 tumors) in the nonvascular sarcomatous cells. Conclusions: The range of immunophenotypical expression is likely to be a reflection of the capacity of a multipotential progenitor to undergo divergent differentiation. There is very little morphological difference between the postirradiated and nonirradiated tumors except that a higher proportion of postirradiated tumors are immunoreactive to SMA and desmin.
\end{abstract}

RÉSUMÉ: Gliosarcomes irradiés et non irradiés: profil immunophénotypique. Introduction: Trente-et-un gliosarcomes ( 25 non irradiés et 6 irradiés) ont été étudiés à cause de la présence de deux zones tumorales distinctes, soit une composante gliomateuse maligne et une composante sarcomateuse. Dans tous les cas, la composante sarcomateuse ressemblait à un fibrosarcome ou à un histiocytome fibreux malin. Deux tumeurs avaient en plus des zones de différenciation ostéochondrö̈de. Méthodes: Toutes les tumeurs ont été examinées au moyen d'anticorps dirigés contre l'agglutinine Ulex europaeus I (AUE), la protéine acide fibrillaire gliale (PAFG), la vimentine (VM), l'antigène de la membrane épithéliale (AME), la desmine, le collagène IV, l'alpha-l-antitrypsine (-I-AT) et l'actine du muscle lisse (AML). Résultats: Alors que le VM révélait les zones sarcomateuses de toutes les tumeurs, il n'y avait que quelques cellules fusiformes éparpillées qui étaient positives pour la PAFG dans ces mêmes zones. Il y avait une réaction diffuse à l'-1-AT dans les zones sarcomateuses chez 20 cas. Une immunoréactivité a été observée à l'AML (20 tumeurs), à l'AUE ( 8 tumeurs), à l'AME ( 5 tumeurs), au collagène IV (5 tumeurs) et à la desmine (4 tumeurs) dans les cellules sarcomateuses non vasculaires. Conclusion: La plage d'expression immunophénotypique est probablement un reflet de la capacité d'un progéniteur multipotentiel à subir une différenciation divergente. Il y a peu de différences morphologiques entre les tumeurs irradiées et non irradiées sauf qu'il y a une proportion plus élevée de tumeurs irradiées qui ont une immunoréactivité à l'AMS et à la desmine.

Can. J. Neurol. Sci. 1996; 23: 251-256

Gliosarcoma (GS) is a tumor consisting of 2 distinctive components, namely the gliomatous and the sarcomatous elements. ${ }^{1}$ A sarcomatous stroma occurs in about $2 \%$ to $8 \%$ of the malignant gliomas. ${ }^{2,3}$ Though prognostically, there is not very much difference between glioblastoma multiforme and GS, the diverse morphological representation of GS has led to controversies concerning its histogenesis. It is still uncertain whether the sarcomatous component arises from the hyperplastic vascular elements of a glioblastoma (e.g., endothelium or smooth muscle) or a multi-potential mesenchymal precusor. Furthermore, while most would consider the sarcomatous component to derive from the malignant glioma, mainly glioblastoma, there are instances where the reactive gliosis responding to a primary intracranial sarcoma transforms into a malignant glioma, giving rise to an entity named sarcoglioma. ${ }^{4.5}$ Morphologically, it could be very difficult to differentiate a sarcoglioma from a GS.

From the Division of Pathology, (L.C.A., E.P., B.Y.); and Division of Neurology (J.R.P.), Sunnybrook Health Science Centre, and Department of Pathology. (J.M.B., W.O.. N.N.), St. Michael's Hospital, University of Toronto, Toronto.

RECEIVED NOVEMBER 7. 1995. ACCEPTED IN FINAL. FORM APRIL. I, 1996.

Reprint requests to: Dr. L.C. Ang, Pathology, E419, Sunnybrook Health Science Centre. University of Toronto, 2075 Bayview Avenue, North York, Ontario, Canada M4N 3M5 
In this paper, 31 gliosarcomas were examined histologically and immunohistochemically to determine the various phenotypical expressions found in the sarcomatous component of the tumor. We also compared the immunohistochemical profile between postirradiated and nonirradiated GS.

\section{Materials and Methods}

We have selected biopsies from 31 cases of cerebral gliosarcomas based on the presence of a dimorphic tumor with distinctive malignant gliomatous and sarcomatous components. The histopathological diagnoses were reviewed and confirmed by two of us (LCA and JMB). In all these cases there was sufficient tissue from the paraffin blocks for sections to be cut for immunohistochemistry.

The clinical data such as age, sex and outcome of patients, site of tumor and mode of treatment were also available from hospital records. Twenty-five of these tumors were initially diagnosed as gliosarcomas before the institution of radiotherapy and chemotherapy. The other six GS were biopsied or resected after irradiation to a primary malignant glial tumor.

Immunohistochemistry using the avidin-biotin conjugation method $^{(6)}$ was performed on paraffin sections with antibodies against: 1) glial fibrillary acid protein (GFAP), 2) vimentin, 3) desmin, 4) epithelial membrane antigen (EMA), 5) smooth muscle actin (SMA), 6) collagen IV and 7) alpha- 1 -antitrysin ( $\alpha-1$ AT) and 8) ulex europaeus agglutinin-1 (UEA-1). These sections were counterstained with hematoxylin. The primary antibodies, the dilutions used and their sources are shown in Table 1.

\section{Results (see Table 2)}

All the tumors had prominent spindle cell components in the sarcomatous areas which resemble either fibrosarcoma, malignant fibrous histiocytoma or both. Morphologically, using the routine hematoxylin-eosin preparation it was not possible to distinguish the postirradiated and nonirradiated GS. The sarcomatous components are heavily stained with reticulin which outlines the individual tumor cells. In addition to the spindle cell sarcoma, two tumors showed osteochondral differentiation, of

Table 1. Primary antibodies used in the immunostaining.

\begin{tabular}{|c|c|c|c|}
\hline & Reagent & Dilution & Source \\
\hline 1. & GFAP & $1: 400$ & $\begin{array}{l}\text { Dako Corp } \\
\text { Carpinteria, CA, USA }\end{array}$ \\
\hline 2. & Vimentin & $1: 400$ & $\begin{array}{l}\text { Progen } \\
\text { Heidelberg, FRG Laboratories }\end{array}$ \\
\hline 3. & Desmin & $1: 200$ & $\begin{array}{l}\text { BioGenex } \\
\text { San Ramon, CA, USA }\end{array}$ \\
\hline 4. & EMA & $1: 40$ & $\begin{array}{l}\text { Dako Corp } \\
\text { Carpinteria, CA, USA }\end{array}$ \\
\hline 5. & SMA & $1: 200$ & $\begin{array}{l}\text { Dako Corp } \\
\text { Carpinteria, CA, USA }\end{array}$ \\
\hline 6. & UEA-1 & $1: 400$ & $\begin{array}{l}\text { Dako Corp } \\
\text { Carpinteria, CA, USA }\end{array}$ \\
\hline 7. & Collagen IV & $1: 200$ & $\begin{array}{l}\text { Enzo Biochem Inc } \\
\text { Farmingdale, NY, USA }\end{array}$ \\
\hline 8. & $\alpha-1-A T$ & $1: 800$ & $\begin{array}{l}\text { Dako Corp } \\
\text { Carpinteria, CA, USA }\end{array}$ \\
\hline
\end{tabular}

Table 2. Immunoreactivity in gliosarcoma. $\mathrm{n}=31(6)^{\mathrm{a}}$

\begin{tabular}{lcc}
\hline & Sarcomatous Component & Gliomatous Component \\
\hline GFAP & $0^{\mathrm{b}}$ & $31(6)$ \\
Vimentin & $31(6)$ & $31(6)$ \\
Desmin & $4(3)$ & 0 \\
EMA & $5(0)$ & 0 \\
SMA & $17(5)$ & 0 \\
Ulex & $8(1)$ & 0 \\
Collagen IV & $3(1)$ & 0 \\
$\alpha-1$-AT & $22(3)$ & $31(6)$ \\
\hline
\end{tabular}

a - parentheses apply to postirradiated cases

b - isolated spindle cells are GFAP-positive in all cases

which one definitely exhibited osteosarcomatous features (Figure 1).

GFAP was reactive in the gliomatous component of all tumors but in the sarcomatous areas only scattered single cells were immunoreactive (Figure 2). Some of these positive cells had radiating cytoplasmic processes resembling astrocytes, but others were spindle cells and had more semblance to the surrounding sarcomatous cells (Figure 3).

Desmin was expressed in the cytoplasm of occasional large pleomorphic cells in the sarcomatous component of 4 cases. Three tumors were postirradiated GS and only one belonged to the nonirradiated group. Morphologically, some of these cells had multiple nuclei and eosinophilic cytoplasm resembling rhabdomyoblasts but no cross-striations were noted (Figure 4).

SMA was expressed in the wall of hyperplastic blood vessels in the gliomatous and sarcomatous areas. In addition it was seen in the sarcomatous cells adjacent to or away from the blood vessels in 20 tumors (Figure 5). Five out of the 6 postirradiated tumors (83\%) expressed SMA whereas 15 out of 25 of the nonirradiated tumors showed SMA reactivity $(60 \%)$. In all of these the immunostaining was restricted to small foci and not diffusely present throughout the tumors. The staining in the large blood vessels within the tumors containing smooth muscle served as a good control. The UEA-1 was expressed in the sarcomatous cells in 8 tumors (only one postirradiated tumor) though it was

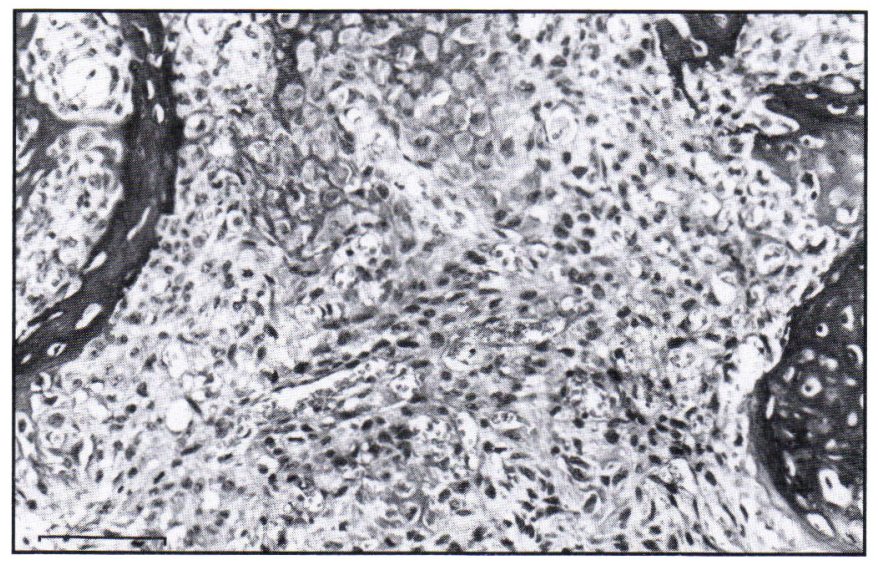

Figure 1: Gliosarcoma with osteosarcomatous change. (Hematoxylineosin; magnification bar $=82 \mu$ ) 
seen in virtually all the endothelial cells regardless of size and location of the blood vessels. This antigen was only focally expressed either as individual cells, small clusters or trabeculae in the sarcomatous areas (Figure 6).

The $\alpha-1$-AT showed background staining but heavy and diffuse immunoreactivity was noted in the spindle cell sarcomatous component in 20 cases with much lighter reactivity in the gliomatous component (Figure 7). The immunoreactive areas in the sarcoma had either a storiform or interlacing pattern. EMA was reactive focally in the sarcomatous areas in 5 cases. There was no resemblance of these cells to meningiotheliomatous cells. No EMA immunostaining was noted in the gliomatous cells. Collagen IV was noted in the basement membrane of blood vessels especially the normal appearing vessels. In 4 cases of GS, this antigen was also expressed focally in the sarcomatous cells. No collagen IV reactivity was seen in the gliomatous cells. Vimentin is expressed in endothelium, and diffusely in the gliomatous and sarcomatous areas in all the tumors; however, the sarcomatous cells were definitely more vimentin reactive than the glial cells (Figure 8).

\section{Discussion}

Regardless of whether the sarcomatous component of GS appears similar to fibrosarcoma or malignant fibrous histiocytoma,

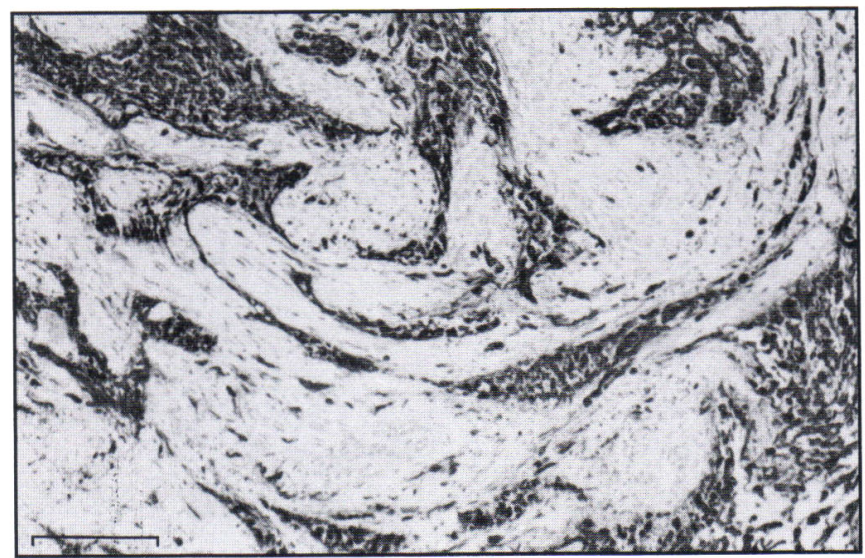

Figure 2: The sarcomatous component is GFAP-negative except for isolated cells while the gliomatous component is intensely GFAP-positive. $(G F A P$, magnification bar $=164 \mu)$

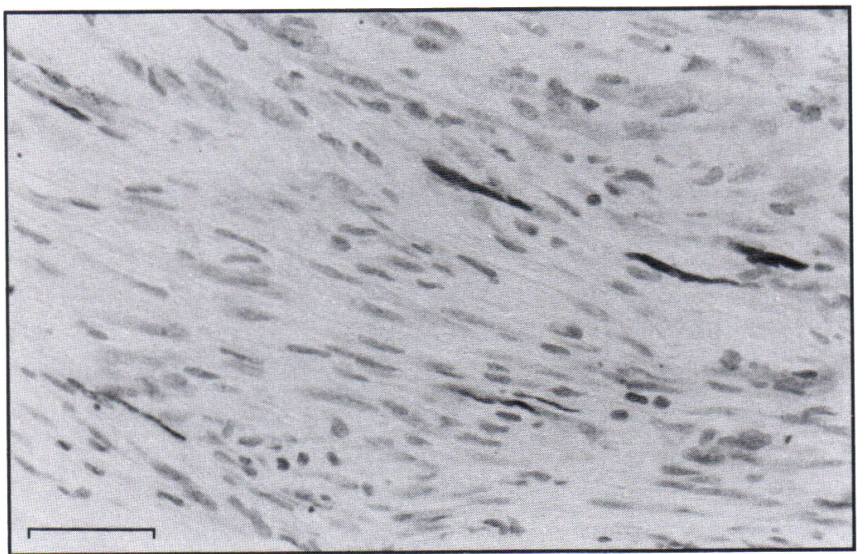

Figure 3: GFAP-positive spindle shaped cells in the sarcomatous area. (GFAP, magnification bar $=4 I \mu$ )

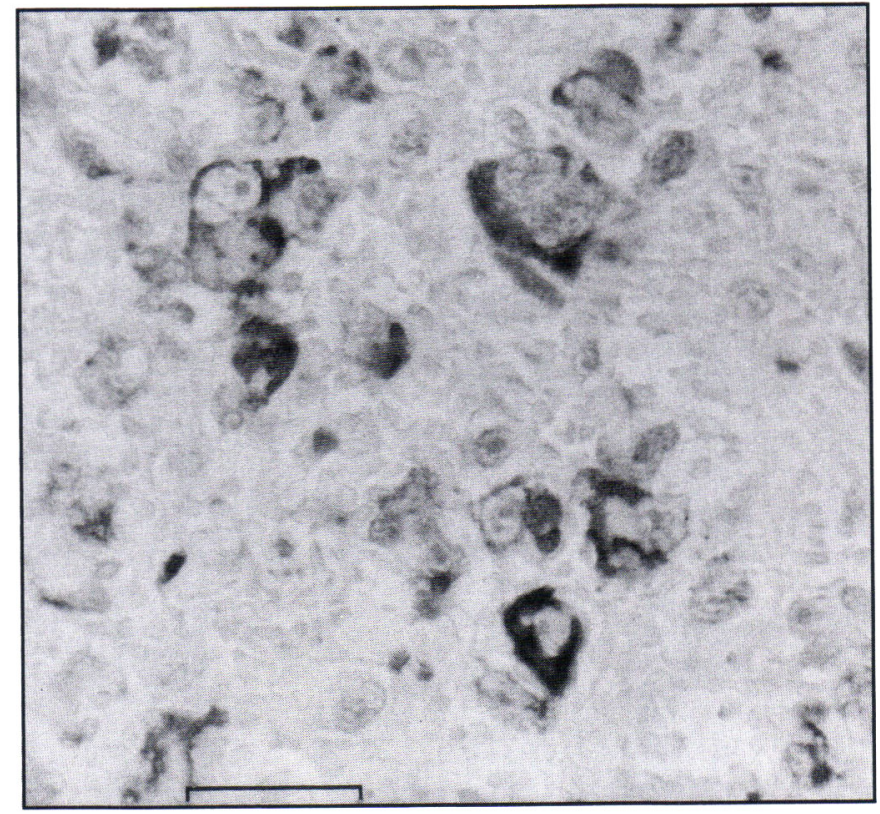

Figure 4: Only occasional pleomorphic cells, including cells with more than one nuclei are desmin-positive. (Desmin, magnification bar $=25 \mu$ )

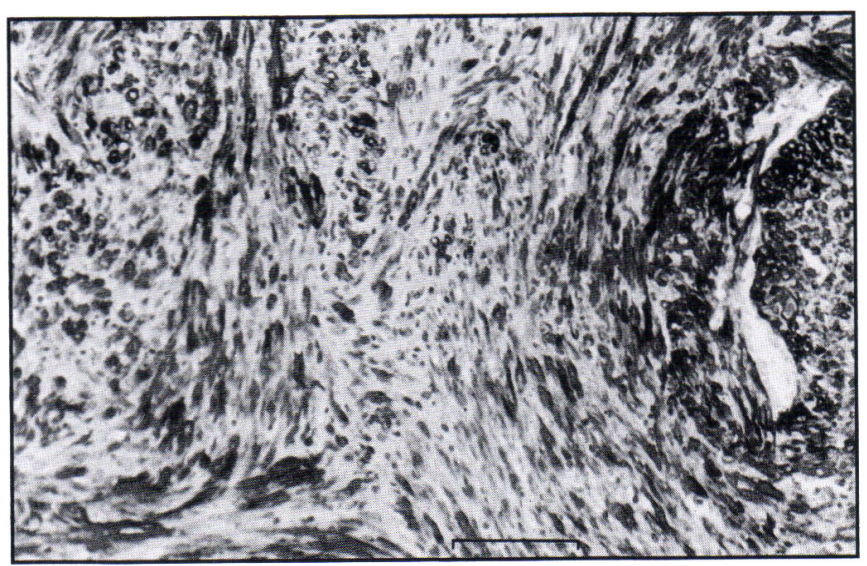

Figure 5: The SMA immunoreactivity in the blood vessel wall and the surrounding sarcoma cells. (SMA, magnification bar $=4 l \mu)$

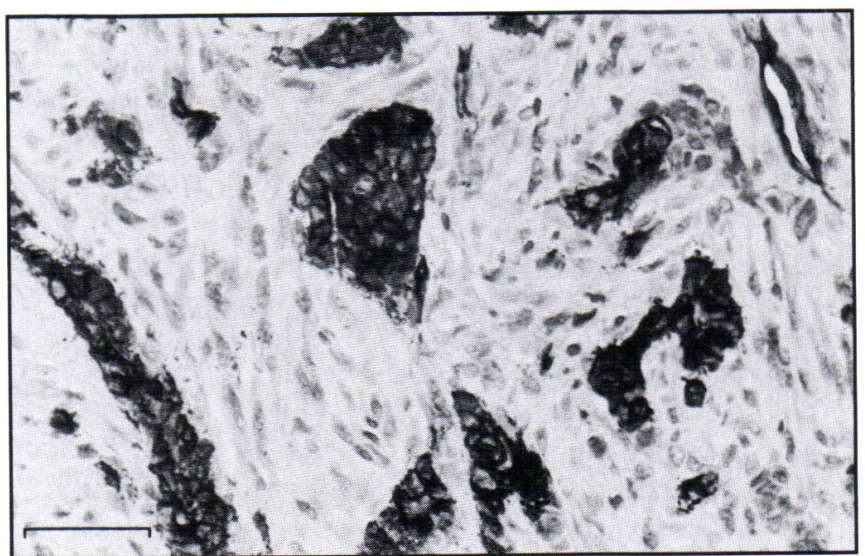

Figure 6: Ulex reactivity is noted in small blood vessels and sarcomatous cells. (UEA-1, magnification bar $=4 l \mu)$ 


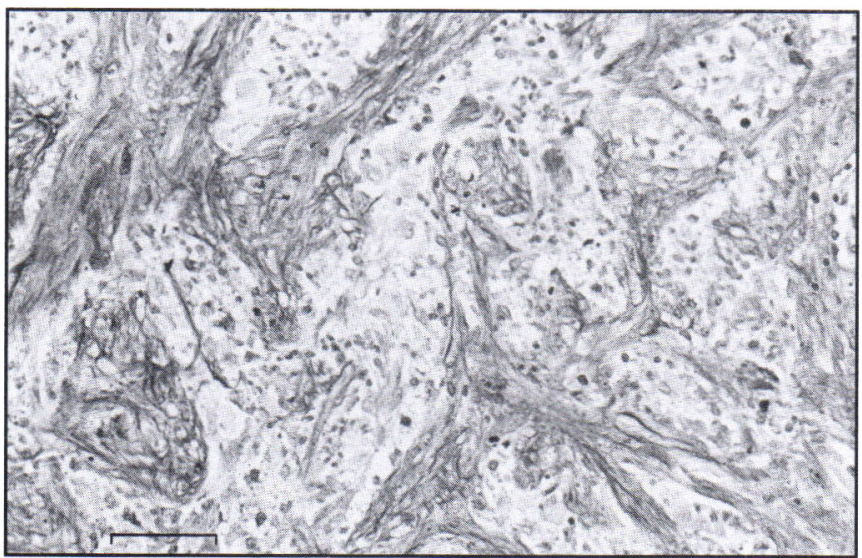

Figure 7: The sarcomatous areas have more intense $\alpha-I-A T$ reactivity than the gliomatous areas. $(\alpha-1-A T$, magnification bar $=65 \mu)$

the vimentin was intensely reactive in all cases pointing to its mesenchymal nature. ${ }^{7.8}$ While GFAP is generally non-reactive in the sarcomatous areas, there are isolated individual cells which are GFAP-positive. These could either be trapped glioma cells, reactive astrocytes or isolated sarcoma cells with glial differentiation. While the presence of these GFAP reactive cells were often not well recognized previously, Jones et al. ${ }^{9}$ have identified GFAP-positive spindle cells in the reticulin-rich areas of the GS. Based on this finding, they have suggested that most of the "mesenchymal" areas of GS are actually gliomatous and therefore GS should be re-designated as "spindle-cell glioblastoma". Their interpretations, though interesting, have remained rather controversial. ${ }^{10}$

The $\alpha-1$-AT was diffusely reactive in the sarcomatous component of $20 \mathrm{GS}$. In many immunoreactive areas the morphological features of these tumors could resemble either malignant fibrous histiocytoma, fibrosarcoma or both. Though $\alpha-1$-AT is not a specific histocytic marker, 711 previous ultrastructural studies have also demonstrated the presence of histiocytic cells in GS. ${ }^{12}$ These $\alpha-1$-AT cells are not only found to comprise a major proportion in some GS by Kochi et al. ${ }^{13}$ but they also suggest that these cells promote sarcomatous proliferation of other mesenchymal cells by mediating the production of fibronectin.

The UEA-1 was reactive in the nonvascular element of the sarcomatous areas in only 8 cases and the extent of reactivity was less than SMA in most cases. In 4 of these cases there was also focal SMA expression though not exactly in the same areas. The immunoreactivity of UEA-I and factor VIII was reported in the sarcomatous areas of GS in previous studies. ${ }^{7.14,15}$ In fact, Weibel-Palade bodies, a marker for endothelial cells were also identified in the tumor cells on electron microscopy. ${ }^{14}$ This immunophenotypical expression of endothelial antigen in the nonvascular sarcomatous cells of GS has also been used as evidence to support the derivation of GS from the hyperplastic endothelial cells in malignant gliomas.

SMA expression was noted in the $20 \mathrm{GS}$ in a focal rather than diffuse manner. The fact that SMA was seen in the vascular elements of glioblastoma led Haddad and co-workers ${ }^{16.17}$ to postulate that GS is derived from the smooth muscle component of the proliferative vascular element in glioblastoma. They felt that malignant glia could induce the proliferation and malignant transformation of smooth muscle in the vascular elements

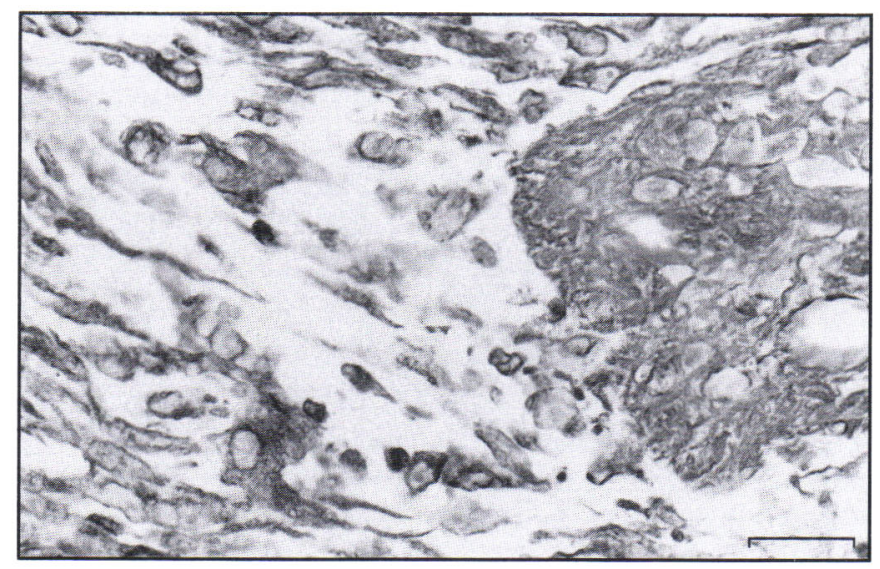

Figure 8: The vimentin immuoreactivity is more intense highlighting the individual sarcomatous cells. The gliomatous area show's less intense reaction. (Vimentin, magnification bar $=24 \mu$ )

through the paracrine influence. Platelet-derived, fibroblast growth factors and other factors produced by glioblastomas are known to be smooth muscle mitogens. ${ }^{18-22}$ The platelet-derived growth factor has also been shown to have oncogenic effect. ${ }^{23}$ It is suggested that radiotherapy and/or chemotherapy could facilitate the malignant transformation of smooth muscle cells in malignant glioma. ${ }^{17}$ This could explain the high proportion of postirradiated GS (5 out of 6) with SMA expression in our study. Interestingly, of the four GS used by Haddad et al. ${ }^{17}$ to demonstrate smooth muscle expression, three of them had prior irradiation. The focal nature of smooth muscle differentiation, however, needs to be explained. One possibility is that these tumors may have been derived from smooth muscle within the vascular element of GBM but underwent de-differentiation resulting in the loss of smooth muscle expression in most areas. Alternatively, the sarcomatous and gliomatous components could have shared a common origin and the smooth muscle differentiation is one example of the divergent differentiation of this multipotential progenitor. The studies of $p 53$ protein immunohistochemistry and $p 53$ gene mutation lend support to the notion that a common progenitor gives rise to both glial and sarcomatous components in at least some GS. ${ }^{24,25}$ Albrecht et al. ${ }^{24}$ using immunohistochemistry have shown that the mutant p53 protein is expressed in both glial and sarcomatous areas in all the 8 GS studied. Subsequently, single-strand confirmation analysis and direct DNA sequencing have demonstrated identical p53 protein gene mutation in both glial and sarcomatous components in two tumors. ${ }^{25}$

Unlike the report of Barnard et al. ${ }^{26}$ on a rhabdomyosarcoma arising from a malignant glioma, the rhabdomyoblastic differentiation in our four cases was very focal and would not have been detected if not for the desmin immunostaining. Such focal differentiation towards skeletal muscle has been well described in malignant peripheral nerve tumors and may reflect the multipotentiality of certain neoplastic cells. ${ }^{27}$ As for central nervous system tumors, such differentiation could be seen in medullomyoblastoma $\mathrm{a}^{28}$ and very rare cases of cerebral medullo-epithelioma. ${ }^{29}$ Significantly, 3 out of 4 cases are postirradiated tumors, raising the remote possibility of a relationship between irradiation and rhabdomyoblastic transformation. 
After reviewing a significant number of GS, we have found that such tumors could exhibit morphological features of fibrosarcoma, malignant fibrous histiocytoma and osteochondrosarcoma. ${ }^{30-32}$ As well, immunostaining of epithelial (EMA immunoreactivity), glial, mesenchymal, histiocytic, skeletal and smooth muscle cells has been noted in the sarcomatous component. While there is considerable difference in opinion as to the cell of origin in GS, we feel that the various phenotypical expressions in this tumor are merely a reflection of the capacity of multipotential mesenchymal elements to undergo divergent differentiation. Such divergent differentiation is seen in some other malignant tumors. One such example is a group of malignant peripheral nerve tumors which shows focal rhabdomysarcomatous, osseous, chondroid and epithelial differentiation. ${ }^{27}$

The relation between irradiation of GBM and the histogenesis of GS remains uncertain. ${ }^{14,17,33}$ Other radiation-induced cerebral and meningeal sarcomas, however, appear several years after the radiation..$^{34-39}$ In our cases of GS, the mean time between the original radiation and the confirmation of diagnosis is about 9 months; ${ }^{40}$ a period too short to suggest that the sarcomatous changes are entirely due to irradiation. Previous pathological studies on GS have not looked specifically at the difference between postirradiated and nonirradiated tumors. ${ }^{3}$ Morphologically, it was not possible for us to distinguish the differences between postirradiated and nonirradiated GS using routine preparations such as a hematoxylin-eosin stain. Although the number of irradiated tumors in the present study is small, we have noted that SMA and desmin immunoreactivity was present in a greater proportion of postirradiated than nonirradiated GS. Previously, Haddad et al. ${ }^{17}$ have suggested the possibility that irradiation could facilitate the differentiation of neoplastic mesenchymal cells along the line of smooth muscle. Although our findings appear to support their ideas, further studies are necessary before any definite conclusion could be drawn.

\section{ACKNOWLEDGEMENTS}

The authors thank Norma Blythe and Lina Paolucci for assistance with the manuscript.

\section{REFERENCES}

1. Feigin IH, Gross SW. Sarcoma arising in glioblastoma of the brain. Am J Pathol 1955; 31: 633-653.

2. Morantz RA, Feigin I, Ransohoff J, III. Clinical and pathological study of 24 cases of gliosarcoma. J Neurosurg 1976; 45: 398408.

3. Meis JM, Martz KL, Nelson JS. Mixed gliobastoma multiforme and sarcoma. Cancer 1991; 67: 2342-2349.

4. Rubinstein LJ. The development of continuous sarcomatous and gliomatous tissue in intracranial tumour. J Pathol Bact 1956; 71 : $441-459$.

5. Lalitha VS, Rubinstein LJ. Reactive glioma in intracranial sarcoma: a form of mixed sarcoma and glioma ("sarcoglioma") Report of eight cases. Cancer 1979; 43: 246-257.

6. Hsu S-M, Raine $L$ and Fanger $H$. Use of avidin-biotin-peroxidase complex $(\mathrm{ABC})$ in immunoperoxidase technique: a comparison between $\mathrm{ABC}$ and unlabelled antibody (PAP) procedures. J Histochem Cytochem 1981; 29: 577-580.

7. Grant JW, Steart PV, Aguzzi A, Jones DB, Gallagher PJ. Gliosarcoma: an immunohistochemical study. Acta Neuropathol 1989; 79: 305-309.
8. Meis JM, Ho K-L, Nelson JS. Gliosarcoma. A histologic and immunohistochemical reaffirmation. Modern Pathol 1990; 1: 1924.

9. Jones H, Steart PV, Weller RO. Spindle-cell glioblastoma or gliosarcoma? Neuropathol Appl Neurobiol 1991; 17: 177-187.

10. Paulus W, Jellinger K. Desmoplastic spindle-cell glioblastoma or gliosarcoma? Neuropathol Appl Neurobiol 1992; 18: 207-208.

11. Leader M, Patel J, Collins M, Henry K. Anti-alpha-1-antichymotrypsin staining of 194 sarcomas, 38 carcinomas and 17 malignant melanomas. Its lack of specificity as a tumour marker. Am J Surg Pathol 1987; 11: 133-139.

12. Ho K-L: Histogenesis of sarcomatous component of the gliosarcoma. An ultrastructural study. Acta Neuropathol 1990; 81: 178-188.

13. Kochi N, Budka H. Contribution of histiocytic cells to sarcomatous development of the gliosarcoma. Acta Neuropathol 1987; 73: 124-130.

14. Slowik F, Jellinger K, Gaszó L, Fischer J. Gliosarcomas: histochemical, ultrastructural, and tissue culture studies. Acta Neuropathol (Berl) 1985; 67: 201-210.

15. Cerda-Nicolas $M$, Kepes JJ. Gliofibromas (including malignant forms), and gliosarcomas: a comparative study and review of the literature. Acta Neuropathol 1993; 85: 349-361.

16. Haddad SF, Moore SA, Schelper RL, Goeken JA. Vascular smooth muscle hyperplasia underlies the formation of glomeruloid vascular structures of glioblastoma multiforme. J Neuropathol Exp Neurol 1992; 51, 5: 488-492.

17. Haddad SF, Moore SA, Schelper RL, Goeken JA. Smooth muscle can comprise the sarcomatous component of gliosarcomas. J Neuropathol Exp Neurol 1992; 51, 5: 493-498.

18. Betsholtz C, Heldin $\mathrm{CH}$, Nister M, et al. Synthesis of a PDGF-like growth factor in human glioma and sarcoma cells suggests the expression of the cellular homologue to the transforming protein of simian sarcoma virus. Biochem Biophys Res Commun 1983; 117: 176-182.

19. Hermansson $M$, Nister $M$, Betsholtz $C$, et al. Endothelial cell hyperplasia in human glioblastoma. Coexpression of mRNA for platelet-derived growth factor (PDGF) B chain and PDGF receptor suggests autocrine growth stimulation. Proc Natl Acad Sci USA 1988; 85: 7748-7752.

20. Ikeda U, Ikeda M, Oohara T, Kano S, Yaginuma T. Mitogenic action of interleukin-1A on vascular smooth muscle cells mediated by PDGF. Atherosclerosis 1990; 84: 183.

21. Paulus W, Grothe C, Sensenbrenner M, et al. Localization of basic fibroblast growth factor, a mitogen and angiogenic factor, in human brain tumours. Acta Neuropathol 1990; 79: 418-423.

22. Mansson PE, Malark M, Sawada H, Kan M, McKeehan WL. Heparin-binding (fibroblast) growth factors type one and two are co-expressed in proliferating normal human vascular endothelial and smooth muscle cells in culture. In: Vitro Cell Dev Biol 1990; 26: 209-212

23. Antoniades HN. Platelet-derived growth factor and malignant transformation. Biochem Pharmacol 1984; 33: 2823-2828.

24. Albrecht $S$, Conelly JH, Bruner JM. Distribution of p53 protein expression in gliosarcoma: an immunohistochemistry study. Acta Neuropathol 1993; 85: 222-226.

25. Biernat W, Aguzzi A, Sure U, et al. Identical mutations of the p53 tumour suppressor gene in the gliomatous and the sarcomatous components of gliosarcomas suggest a common origin from glial cells. J Neuropathol Exp Neurol 1995; 54: 651-656.

26. Barnard RO, Bradford R, Scott T, Thomas DGT. Gliomyosarcoma: report of a case of rhabdomyosarcoma arising in a malignant glioma. Acta Neuropathol (Berl) 1986; 69: 23-27.

27. Engzinger M, Sharon W. Soft Tissue Tumour, 3rd Edition, 889-928, Mosby, St. Louis, Mo., 1995.

28. Smith TW, Davidson RI. Medullomyoblastoma: a histologic, immunohistochemical and ultrastructural study. Cancer 1984, 54: 323-332.

29. Auer RN, Becker LE. Cerebral medulloepithelioma with bone, cartilage and striated muscle. Light-microscopic and immunohistochemical study. J Neuropathol Exp Neurol 1983; 42: 256 267.

30. Hayashi $\mathrm{K}$, Ohara $\mathrm{N}$, Jeon $\mathrm{HJ}$, et al. Gliosarcoma with features of chondroblastic osteosarcoma. Cancer 1993; 72: 850-853. 
31. Sarmiento J, Ferrer I, Pons L, Ferrer E. Cerebral mixed tumour osteo-condrosarcoma - glioblastoma multiforme. Report of one case. Acta Neurochir 1979; 50:335-341.

32. Tada T, Katsuyama T, Aoki T, Kobayashi S, Shigematsu H. Mixed glioblastoma and sarcoma with osteoid-chondral tissue. Clin Neuropathol 1987; 6: 160-163.

33. Louis DN, Hedley-Whyte ET, Martuza RL. Sarcomatous proliferation of the vasculature in a subependymoma: a followup study of sarcomatous dedifferentiation. Acta Neuropathol 1990; 80: 573-574.

34. Averback P. Mixed intracranial sarcomas. Rare forms and a new association with previous radiation therapy. Ann Neurol 1978; 4: 229-233.

35. Noetzli M, Malamud N. Postirradiation fibrosarcoma of the brain. Cancer 1962; 15: 617-622.
36. Bernstein M, Perrin RG. Platts ME, Simpson WJ. Radiationinduced cerebellar chondrosarcoma: case report. J Neurosurg 1984; 61: 174-177.

37. Gonzalez-Vitale IC, Slavin RE, McQueen JD. Radiation-induced intracranial malignant fibrous histiocytoma. Cancer 1976; 37 : 2960-2963.

38. Schrantz JL, Araoz CA. Radiation induced meningeal fibrosarcoma. Arch Pathol 1972; 93: 26-31.

39. Waltz TA, Brownell B. Sarcoma: a possible late result of effective radiation therapy for pituitary adenoma; report of two cases. J Neurosurg 1966; 24: 901-907.

40. Perry JR, Ang LC. Bilbao JM, Muller PJ. Clinicopathologic features of primary and postirradiation cerebral gliosarcoma. Cancer 1995; 75: 2910-2918. 